Article

\title{
An Institutional Analysis of Groundwater Quality Control: Experiences in Hadano, Kanagawa Prefecture, Japan
}

\author{
Takahiro Endo
}

College of Sustainable System Sciences, Osaka Prefecture University, Sakai, Osaka Prefecture 599-8531, Japan; tte23042@osakafu-u.ac.jp; Tel.: +81-72-254-9646

Academic Editor: Tamim Younos

Received: 29 December 2015; Accepted: 4 May 2016; Published: 18 May 2016

\begin{abstract}
A considerable number of studies have been made of institutional arrangements that can prevent excessive groundwater pumping based on Hardin's seminal work, the "tragedy of the commons." In contrast, this paper is concerned with groundwater quality control for which policy studies are very limited. This paper not only clarifies institutional challenges specific to groundwater contamination, but also demonstrates how government and industry could solve them using a case study of Hadano, Kanagawa Prefecture, Japan, which has pioneered countermeasures for groundwater pollution in Japan. Hadano solved the challenges by enacting an innovative local ordinance with three pillars: Proxy purification by the city government, fundraising for purification activities and a retroactive system. Lessons learnt from the Hadano case will be very useful to policy makers because these problems already occur in other urban areas, or are likely to occur in the near future.
\end{abstract}

Keywords: common-pool resources; commons; groundwater; groundwater quality; contamination; retroaction; proxy execution; the polluter-pays principle; Japan

\section{Introduction}

Research into managing common-pool resources has gradually developed since Hardin's seminal work on the "tragedy of the commons" [1]. A central theme of the research is to find institutional arrangements that can prevent wasteful use of common-pool resources [2]. Common-pool resources have two characteristics: Difficulty of exclusion and rivalness of consumption. Difficulty of exclusion implies that controlling a range of beneficiaries through physical or institutional means can be prohibitively expensive. Rivalness of consumption means that someone's consumption of the resource reduces the potential consumption of others. Natural resources in general tend to have these common-pool characteristics [3]. Because groundwater exhibits these characteristics, analytical frameworks for common-pool resources study have been applied to groundwater management in different parts of the world.

Lipson explained the development of institutions for groundwater management in Southern California, USA, and showed how various policy options such as a pump tax and tradable permits were implemented to mitigate excessive groundwater pumping [4]. These options cannot always be used in areas because of different legal conditions. Endo compared groundwater management by the Tokyo Metropolitan Government, Japan, and the Orange County Water District in Southern California to clarify legal reasons for the diversity of groundwater management [5]. Although these studies focused only on groundwater, groundwater often connects with surface water. Glennon reported how excessive groundwater pumping reduces the volume of surface water and asserted the importance of integrated management of both resources [6]. Lastly, Ostrom conducted a wide review of case 
studies on common-pool resources management, including groundwater management in Southern California, and hypothesized the "design principles"; a set of conditions that are critical to sustainable institutional arrangements for common-pool resources in general $[7,8]$.

While the majority of these studies focused on the quantitative aspects of groundwater issues, studies that were concerned with institutional responses to water quality degradation are very limited [9]. Notable exceptions are studies on assessment methods of water quality. Muttil and Chau analyzed the effectiveness of two machine-learning techniques (artificial neural networks and genetic programming) by applying them to a case study of water quality data from Tolo Harbor, Hong Kong, China [10]. Wang applied another method called a variable fuzzy evaluation model to an assessment of water quality of The Three Gorges, China, and Tsen-Wen River basin, Taiwan, and showed that the model output was more accurate than results from conventional approaches such as water quality indices and the entropy method [11]. Moreover, Zhao developed a new methodology for environmental impact assessment, called the multiple criteria data envelopment analysis, which was innovative in that it could not only consider quantitative factors but also qualitative factors simultaneously in the process of environmental impact assessment [12]. Apart from research on these assessment methods, there are a few institutional analyses of groundwater quality issues mentioned in the literature. Trager and Blomquist discussed groundwater pollution in Southern California with a focus on the roles of court-appointed watermasters. However, they did not clarify in detail how the watermasters promoted groundwater contamination removal $[13,14]$. Vrba mentioned that excessive groundwater pumping might cause quality degradation through seawater intrusion and pointed out the necessity of legal regulations based on the polluter-pays principle. However, he failed to consider cases where this principle is difficult to apply [15].

Although these previous studies contributed to the accumulation of case studies on water quality control, they failed to identify institutional challenges specific to groundwater contamination. These challenges are classified into three groups: identification of parties who are responsible for contamination removal, cost sharing among parties, and retrospective application of regulations. It should be noted that these challenges have already been pointed out by Yoshida [16], but he did not mention how to address them in detail. Thus, the original contribution of this paper is to clarify such challenges and demonstrate how they can be addressed. This paper uses a case study of Hadano, Kanagawa Prefecture, Japan to show how government and industry could solve such challenges. It will provide valuable information for policy-makers in many parts of the world, because the challenges are likely to occur in other areas of groundwater pollution.

The paper is organized as follows: an overview of groundwater management in Japan is provided in Section 2; a brief history of groundwater issues in Hadano is given in Section 3; Section 4 deals with institutional inadequacies in the cleanup of groundwater contamination; Section 5 explains how Hadano and local industry overcame these institutional inadequacies; policy lessons are discussed in Section 6; and an overall summary is provided in Section 7.

\section{Overview of Groundwater Management in Japan}

Surface and underground water connect with each other in the hydrological cycle, except in the case of fossil groundwater. However, laws related to water resources in Japan treat them separately, failing to promote integrated management. While surface water is subject to public regulations, such as a permit system, groundwater is regarded as a part of land ownership and in general no permits are required to use it.

Weak public control of groundwater has caused many problems. Severe land subsidence took place in large cities, such as Tokyo and Osaka, as a result of overexploitation of groundwater after the Second World War. The Industrial Water Law of 1956 [17] and the Law on Regulation of Groundwater Use in Office Building of 1962 [18] were enacted to regulate groundwater pumping. These laws introduced a permit system, but this system was only applied in limited areas where land subsidence had taken 
place. Therefore, there has been no nation-wide permit system for groundwater pumping in Japan thus far [19].

Japanese Environment Agency conducted a national survey on groundwater pollution in 1982 after it learned of the case of serious groundwater pollution by volatile organic compounds (VOCs) in Silicon Valley in the State of California, USA. This survey revealed that similar pollution was taking place in Japan [20]. Since then, how to solve groundwater pollution by chlorinated VOCs (CVOCs), represented by trichloroethylene and tetrachloroethylene, has been a primary issue in groundwater quality control in Japan [21].

There is no centralized groundwater management system in Japan. Rather, lower levels of government such as the prefecture, city and town have developed their own groundwater management policies taking local conditions into consideration. In the field of groundwater pollution control, Hadano in Kanagawa Prefecture provides an important policy model. Hadano pioneered a comprehensive ordinance for groundwater pollution control in Japan, which included rules for the purification of contaminated groundwater, as well as the prevention of groundwater pollution. An alternative choice was to make rules, which stipulate only the prevention of groundwater pollution, as other domestic laws and ordinances did. For example, a national law called the Water Pollution Control Law [22] was amended in 1989 to prohibit infiltration of water containing trichloroethylene and tetrachloroethylene into soil. However, the amended law did not include any rules for groundwater purification [23,24], and without such rules groundwater pollution problems cannot be solved. This is because groundwater pollution is a stock pollution and the problem will remain unsolved if existing pollutants are not removed. This shortcoming is addressed in, and is the strength of Hadano's ordinance. This viewpoint is substantiated because the Water Pollution Control Law was further amended in 1996, following Hadano ordinance, so that it incorporated rules for groundwater purification.

\section{Groundwater Problems in Hadano}

Hadano is a small city in Kanagawa Prefecture, Japan, covering $103.61 \mathrm{~km}^{2}$. The annual precipitation is about $1400-1500 \mathrm{~mm}$. In 2014, the total human population was about 0.16 million [25]. The population of Hadano depends on groundwater for $70 \%$ of their drinking water [26].

The history of groundwater in Hadano shows a progression from quantitative to qualitative issues. In the 1960s, many factories moved into Hadano because of the abundance of groundwater. These factories used groundwater so intensively that the groundwater table declined sharply. The city then initiated detailed research to understand the occurrence and flow of groundwater beneath Hadano. The scientific data obtained were widely distributed through local newspapers to raise awareness amongst citizens that groundwater was a shared, but limited resource. This was an exceptional interpretation by any level of government in Japan because groundwater was usually regarded as a part of land ownership. In addition, the city introduced a well registration system, and started artificial groundwater recharge to restore the groundwater table. The city government initially planned to finance artificial recharge by raising domestic water prices. However, the local residents-the main domestic water users-complained, asserting that the factories, which were the major groundwater users, should pay the costs. In response to this complaint, the government created a "cooperative groundwater fund" and asked local factories to contribute to the fund [27].

In the late 1980s, groundwater quality problems were identified in spring water. There are many natural springs in Hadano. The Kobo spring is the most famous one, and is Hadano's icon as a city of groundwater. In January 1989, it was revealed that the water of the Kobo spring was seriously contaminated by tetrachloroethylene. Hadano citizens became aware of the groundwater contamination from commercial magazines, newspapers, and government reports. The city government analyzed the water and found tetrachloroethylene levels of $0.021 \mathrm{mg} / \mathrm{L}$, which was twice as high as the drinking water standard. The city government also found that groundwater contamination had spread to an area of $12 \mathrm{~km}^{2}$ alongside the Mizunashi River [27] (Figure 1). 
The contamination partly originated from laundries in downtown Hadano, but the main source was factories in the upper Mizunashi River that produced automobile parts and air conditioners.

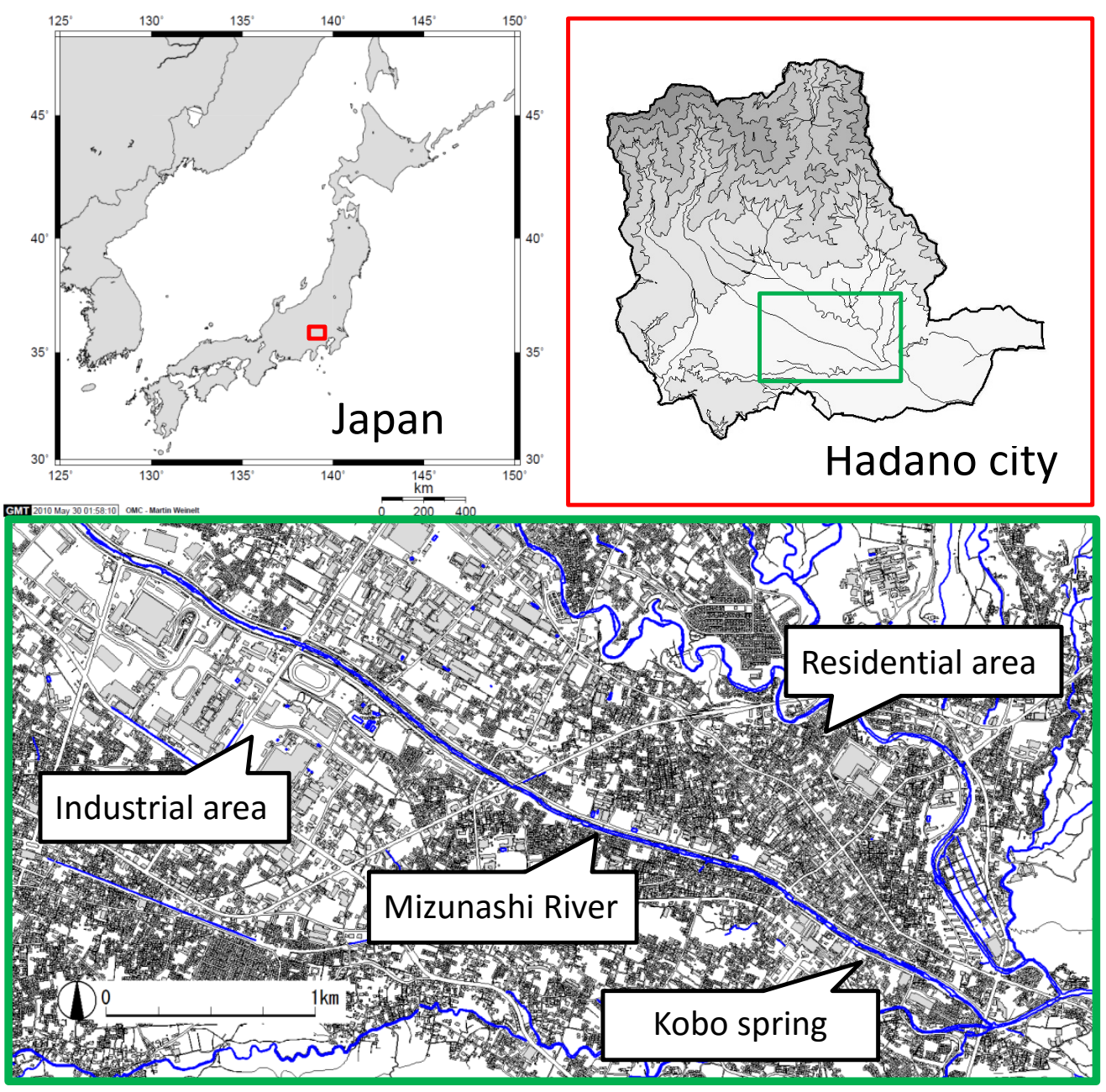

Figure 1. The location of Hadano.

They used CVOCs such as tetrachloroethylene to remove oils attached to the products before sending them to the markets. Although these chemicals were toxic, the industry did not understand such risks and did not handle CVOCs with care. This caused the leakage of tetrachloroethylene from storage tanks within factory sites to groundwater $[21,28]$.

Taking other alternatives into consideration helps us understand why Hadano chose to remove groundwater contamination. One alternative is to leave groundwater pollution untouched. Needless to say, such an option is not a solution. However, according to a survey on groundwater pollution control in 1994, which targeted 56 cities and towns in 12 Prefectures throughout Japan, many local governments did not investigate groundwater pollution because of the high costs, lack of measurement skills, and low dependency on local groundwater [29]. For example, there was the case of Fuchu, a city in Tokyo, where groundwater contamination by trichloroethylene was revealed in 1982. Although the city banned further infiltration of trichloroethylene, it did not take any measures to address existing pollution. This policy was later criticized [30]. In contrast, because of the high dependency on local groundwater, leaving groundwater pollution untouched was not an option for the Hadano government.

A second alternative is to replace contaminated soil with clean soil. Although there were cases where this method was implemented in Hadano, it was not considered to be the preferred solution for the following reasons: (1) Soil excavation is effective where the area of pollution is vertically and 
horizontally limited - this is generally not the case for Hadano; and (2) Hadano was concerned that soil removal would incur additional costs. The main source of pollution was factories in the upper Mizunashi River. If soil removal had been widely implemented, these factories would have had to be demolished, or stop production temporarily [27].

The third alternative is to change water supply from groundwater to surface water. The Hadano government took emergency measures to close some contaminated wells and provide tap water for 45 households whose drinking water entirely depended on such wells. The Hadano government bore all the costs [27]. The total human population of Hadano in the early 1990s was about 0.15 million [25]. Thus, if the city had decided to shut down all the contaminated wells and switch domestic water supply completely from groundwater to surface, it would have incurred huge costs. It is reasonable to assume that these factors caused Hadano to choose the cleanup of contaminated groundwater as the preferred solution. However, this was not an easy task, as described in the following section.

\section{Institutional Problems in Groundwater Contamination Removal}

Hadano faced the following institutional problems in coping with groundwater contamination: the identification of parties responsible for contamination removal, cost sharing among parties, and retrospective application of regulations [16].

Determining who is responsible for contamination removal is important in groundwater quality management. It seems reasonable that those responsible for the pollution should remove it. However, the polluter does not always exist when the contamination is discovered. For example, assume a factory began its operations using tetrachloroethylene in Hadano in 1960, became bankrupt in 2000, and groundwater pollution was only discovered when the factory site was reclaimed as a residential area in 2015. In these cases, it is not clear who should be in responsible for removing the groundwater pollution (for a concrete example, see Section 5.2).

An additional problem is cost sharing among parties. If the pollution does not move outside of a factory site, cost sharing can be done in such a way that each factory removes the contamination within that site at its own expense. Unfortunately, CVOCs can extend a considerable distance beyond the factory sites. This results in the problem of how cost sharing can be achieved for contamination that spreads outside of a factory site. It is very difficult to determine the extent to which the pollutant from each factory contributes to the overall contamination. In addition, the determination will be further complicated when each factory releases multiple pollutants and causes mixed pollution outside the factory site. These are the complications that Hadano had to address.

The final institutional problem is the retrospective application of regulations-whether or not it is legally defensible to apply regulations to past activities. Assume a factory started its operation in 1960 and began to pollute groundwater in the same year. In 2000, the city government introduced a new ordinance that orders factories to prevent groundwater contamination or to remove the pollutants if it fails to prevent contamination. If the factory continues to pollute after the new regulations are introduced, the city government will require the factory to remediate the pollution. The question then arises of whether the city government can legally apply the same rules to the pollutants that accumulated before 2000. The factory may refuse to comply, asserting that releasing the pollutants in the subsurface environment was not against the law before 2000. In this case, the pollutants that accumulated before 2000 remain, and remediation cannot be achieved.

\section{Groundwater Quality Control in Hadano}

\subsection{The Ordinance on Prevention and Removal of Groundwater Contamination in Hadano}

The Ordinance on Prevention and Removal of Groundwater Contamination in Hadano was enacted in 1993 and took effect a year later [31]. (This ordinance is subsequently referred to as the 1994 Ordinance.) The 1994 ordinance has two aims: the prevention of future groundwater contamination, and the removal of existing groundwater contamination. Before Hadano enacted this ordinance, no local 
or national government in Japan had enacted a law on the removal of groundwater contamination in urban areas. Therefore, for guidance, Hadano referred to the Comprehensive Environmental Response, Compensation, and Liability Act of 1980, of the USA, often referred to as the Superfund Act [32]. This is a pioneering law that established a framework for groundwater purification and cost-sharing rules in the USA. Hadano created its own regulations for groundwater quality management based on this law $[33,34]$.

Regarding the prevention of future groundwater contamination, the ordinance designated 11 materials as target substances. All of them were VOCs and these were selected from 46 materials designated in the national drinking water standards, including mercury, cadmium, and copper. While the city government planned to focus on only three materials (trichloroethylene, tetrachloroethylene and 1,1,1-trichloroethane), the target was expanded to another eight materials (e.g., dichloromethane, carbon tetrachloride), which have similar characteristics to the three materials. If the city government had only paid attention to the three materials above, the prevention of further contamination would have been very ineffectual. An alternative was to cover all 46 materials, but this was impossible under the constraints of budget and human resources. Thus, the target materials were limited to what was thought to be critical in Hadano. In the ordinance, those who use the target materials are required to register with the city government and prevent these materials from infiltrating the soil. Users are also obliged to report the difference between the purchase and usage volumes to prevent accidental infiltration [35].

The 1994 ordinance addressed the institutional problems in three ways [33,35]: First, the following four entities were obliged to remove contamination based on the polluter-pays principle: (1) the entity that currently uses the target substances; (2) the entity that once used the target substances; (3) the entity that collects and delivers the target substance; and (4) the entity the city government deemed responsible. The entity of the last category includes, for example, a seller of the target substances or the parent company whose branch contaminated groundwater in Hadano [36]. These four entities are subsequently referred to as the parties concerned. However, in cases where the parties concerned were not certain, could not be apprehended, or could not afford to remove contamination, the city government removed the contamination on their behalf and the parties concerned were charged for the removal costs later. This was referred to as proxy contamination removal. There was one case where this proxy removal was implemented (see Section 5.2). It should be noted that the current landowner or land occupier was exempt from the responsibility of contamination removal. The Hadano Government believed that charging a landowner or land occupier who was unaware of the past land use was too harsh, and would not be acceptable to citizens. Such an exemption was not basically included in the Superfund Act. Although Hadano referred to the Superfund Act, it modified it so as to be more suitable to Japanese society.

Second, the 1994 ordinance allowed the city government intervention to deal with contamination from factories' sites. Based on the polluter-pays principle, it is possible to require each factory to remove contamination within the site. The same principle can theoretically be applied to contamination that spread beyond the site. However, it was difficult to do so in Hadano because establishing how each factory contributed to the overall contamination, especially where multiple pollutants mixed in complex ways, was almost impossible. This is why Hadano's government intervened to remove contamination out of factories' sites. The city government established a "groundwater purification fund" to finance groundwater purification out of factories' site.

Last, the 1994 ordinance incorporated retroactive application of regulations. This is reflected by the rule that the entity that once used the target substances is charged with contamination removal. This can be justified on three grounds: (a) groundwater is an extremely important resource for Hadano citizens because it supplies the majority of their drinking water; $(b)$ tetrachloroethylene has very little natural attenuation and, therefore, not addressing the past contamination would be a substantial health risk to citizens; and (c) allowing retrospective application enables the city government to deal with future contamination by newly made chemicals whose pollution risks are not yet known $[33,37]$. 


\subsection{Cleanup Process}

The way in which Hadano removed groundwater contamination is now outlined. The city government began by setting purification targets for drinking water standards. The 1994 ordinance set the allowable limits at $0.03 \mathrm{mg} / \mathrm{L}$ for trichloroethylene and $0.01 \mathrm{mg} / \mathrm{L}$ for tetrachloroethylene [27].

For removal activities within factory sites, the city government conducted preliminary investigations to check whether there was contamination or not. If contamination was found, the factory was required to conduct a detailed investigation and submit a plan for pollution removal to the government. The factory was obliged to implement pollution removal following the plan being approved by the city, and to get an inspection from the city when it finished the removal. Soil vapor extraction was a primary method to remove contamination within factory sites. While the cost of the preliminary investigation was paid for by the city, the cost of the detailed investigation and removal activities were assigned to the factory. In this scenario, the polluter-pays principle was applied [27,33].

However, this principle did not always work. There was one case where the proxy execution was implemented. In this case, the pollution was not caused by a factory, but by an individually operated laundry. As mentioned before, a part of the pollution originated from laundries in the downtown area. The laundry used tetrachloroethylene on rented land for their operations, but went bankrupt and absconded. Subsequently, another business owner rented the same land and discovered that groundwater underneath the land was seriously contaminated. After a hearing, the city government admitted that the owner had not caused the pollution. Because the original owner could not be located, the contamination was removed by the city government [36].

Because groundwater contamination within factories was rapidly reduced, the focus was then shifted to pollution spilled outside factories. The city was responsible for removing this contamination because it was difficult to establish which factory the pollution could be attributed to. The pollution moved with the flow of groundwater. That meant the beneficial effects of pollution removal would also spread with the flow. However, the groundwater flow was so slow that it was anticipated that it would take a long time for the groundwater quality of the entire basin to improve. Thus, after 1996, Hadano tried to speed up the improvement of groundwater quality by stimulating the water cycle in the subsurface environment. The city first extracted polluted groundwater at wells installed in the more transmissive geological formations. Then, it removed the pollutants at surface, and injected the purified groundwater to lower areas of the same geological formation. The city named this operation the "artificial dialyzer of groundwater." This had a threefold effect: collection of the pollutants, dilution of the pollution, and speeding up of the groundwater flow [38].

The majority of the revenue in the groundwater purification fund was used to develop ways for artificial dialysis of groundwater. According to section 37 of the 1994 ordinance, the fund consisted of three parts: the city's general budget, donations from the parties concerned, and profit from the fund investment (interest earned on the fund). Theoretically, two other alternatives can be considered on the method of budget collection. The first one is to secure the entire budget by imposing a corrective tax on the parties concerned. Although this morally ideal method was considered in a draft of the 1994 ordinance, it was not implemented. This was partly because a local government in Japan did not have any authority to create a new tax without the consent of the National Diet [28]. The other alternative is to secure the budget by a general tax from the current population. This method may produce a stable budget, but is not effective in stopping further pollution. This is because the link between polluting activities and cleanup responsibility becomes unclear. The method of budget collection in groundwater purification fund was a mixture of these two scenarios. The city government mainly depended on a general tax, but, at the same time, asked the parties concerned for voluntary donations. It is considered that the structure was arranged in order to achieve the prevention of further contamination, as well as financial objectives under existing legal settings.

Figure 2 shows the change in revenue and expenditure with time. It shows that the majority of the revenue came from the city's general budget and not from donations from the parties concerned. This means the polluter-pays principle was not completely applied for pollution spills outside factory 
sites. Figure 2 shows that for expenditure the majority of the fund was created early on, and used in decreasing amounts at later times.

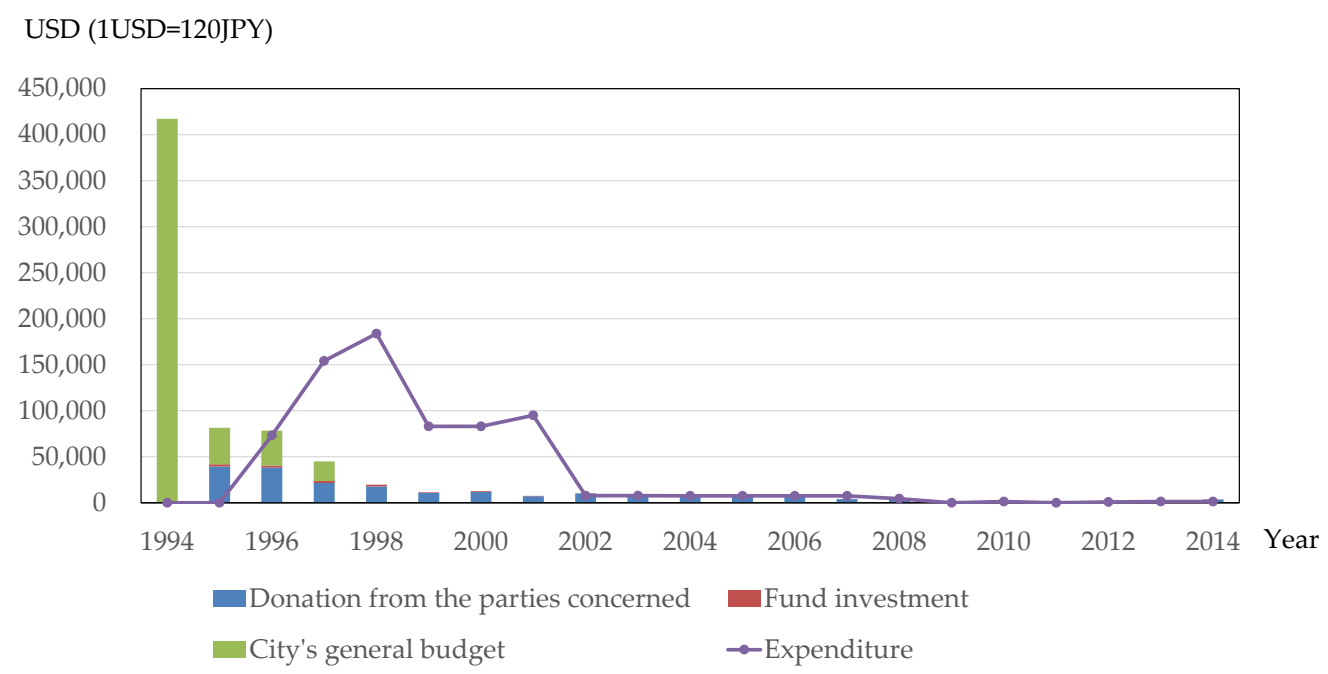

Figure 2. Revenue and expenditure for the groundwater purification fund.

The results of the removal activities are shown in Figure 3. This shows the historical change in tetrachloroethylene concentrations at the Kobo spring. When the contamination was discovered, groundwater at the Kobo spring contained $0.021 \mathrm{mg} / \mathrm{L}$ of tetrachloroethylene, which was twice the drinking water limit. At that time, about 130 entities, including current and past ones, used the target substance. The preliminary investigation by the city found contamination at the premises of 46 entities out of the 130 surveyed. The 46 entities conducted detailed investigations and began to remove the pollutants after 1991. By 2015, 39 entities had completed the removal [39].

Concentration of tetrachloroethylene $(\mathrm{mg} / \ell)$

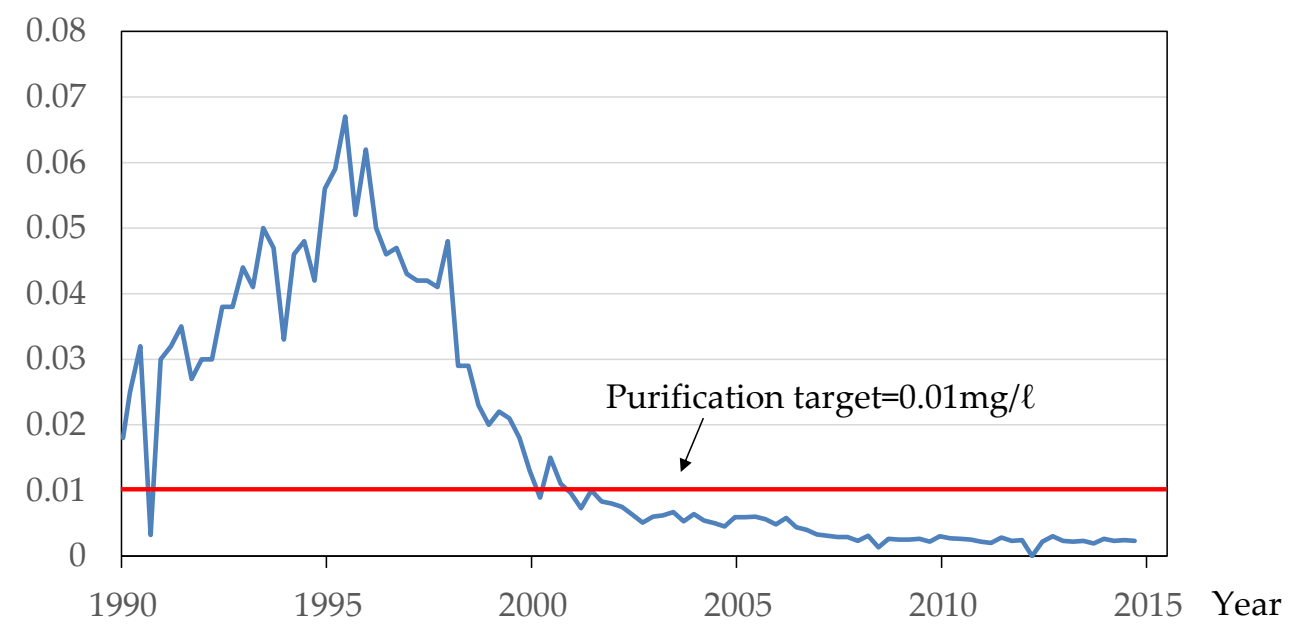

Figure 3. Change in tetrachloroethylene concentrations at the Kobo spring.

Although the pollution removal within factory sites was implemented after 1991, the pollution levels did not initially improve and reached a peak in 1995. This implies that the pollution emanating from the factory sites reached the Kobo spring with a significant time lag. The groundwater quality improved after 1996, which was the year the artificial dialyzer of groundwater was initiated to remove the pollution that had spread beyond the factory sites. Since 2002, Hadano has achieved its purification targets. 


\section{Discussion: Policy Lessons from Hadano's Experience}

As the proverb "prevention is better than cure" suggests, a proactive approach is very important in groundwater quality management. However, the Hadano case shows that proactive measures alone are not enough. Groundwater quality control requires not only rules for the prevention of contamination, but also ones for its remediation. When groundwater contamination was first identified in Hadano, there were no laws for purification of groundwater contamination in Japan apart from a few exceptions such as the Law on Prevention of Soil Contamination in Agricultural Land of 1970 [40] and the Law on Cost Allocation for Prevention of Public Environmental Problems of 1970 [41]. However, these laws could not be applied to urban areas like Hadano because they were enacted for contamination problems in agricultural land. Groundwater contamination in urban areas was not included in legal regulations at that time [34]. Creating a law that focused on the prevention of groundwater contamination and on the cleanup of pollution was the first step in addressing this shortcoming in the legal regulations.

The Hadano case revealed an important exception to the polluter-pays principle. This widely accepted principle means that those who cause the pollution must bear the burden of the purification costs. However, in the case of groundwater contamination, such a polluter does not always exist when the contamination is discovered. This occurs because groundwater contamination is a stock pollution. When the polluter cannot be located, the polluter-pays principle will not lead to a solution because responsibility for remediation cannot be assigned to an entity. Therefore, in designing institutional arrangements for groundwater quality control, it is necessary to specify in advance who is responsible for the cleanup based on the polluter-pays principle, and also to assign responsibilities for cases in which the polluter-pays principle cannot be applied.

Another policy lesson is that attention needs to be given to ways of cost sharing. The cleanup activities were implemented within factory premises and outside of the factories. The parties concerned paid for the costs of the detailed investigations on the pollution and for the pollution removal from within the premises. They also made donations to the groundwater purification fund to remove pollutants outside the premises. In this regard, the polluter-pays principle was applied. However, the city's general budget was also used in both situations. The city conducted preliminary research within the premises and provided substantial financial support to create the groundwater purification fund. The city's general budget originated from tax payments from citizens. This measure can be justified by another principle: the beneficiary-pays principle. The majority of drinking water depends on groundwater in Hadano and the benefit of cleanup activities accrues to the citizens in general. This implies that instead of a single rigid cost-sharing principle, a flexible combination of multiple cost-sharing principles may work better to promote rapid cleanup activities.

The Hadano experience implies a benefit of holistic management of groundwater resources. While quantitative and qualitative aspects are often separately considered in water issues, Hadano's groundwater management pays attention to both issues. This was made possible because groundwater is a shared asset of the citizens of Hadano. Hadano faced a quantitative problem of groundwater depletion. The city conducted detailed research to understand the groundwater occurrence and flow. The scientific data helped raise awareness amongst citizens that groundwater is a shared, but limited resource. This played an important role in coping with groundwater quality problems. For example, donations to the groundwater purification fund are based on the principle that the entity that pollutes the shared asset should take part of the responsibility for the cleanup. It should also be noted that although artificial recharge was originally conducted to protect the shared asset from over-exploitation, the technique was later applied to the injection of purified groundwater to solve quality problems [42]. Hadano initially coped with quantitative problems by developing technical and institutional knowledge and later applied them to tackle the qualitative problem. This implies that although the two problems have distinct causes, they have common solutions.

Lastly, this case shows that the "soft-path approach" and the "hybrid approach" can be extended to water quality problems. According to Gleick [43], the strategies to cope with water scarcity are classified into two groups: "hard-path" and "soft-path." The former is structural and focuses on supply 
enhancement by building dams and desalination plants. In contrast, the latter is a non-structural path that is concerned with demand reduction by creating institutions for water conservation and water transfer. Gleick pointed out that while hard-path approaches have been the main countermeasures to water scarcity throughout the 20th century, much more attention should be paid to soft-path approaches in future water policy. However, there is little research that applies this approach to water quality issues. The Hadano water quality control case involved hard-path focus on the development of cleanup technologies and soft-path attention to institutions that restrict pollution or allocate cleanup responsibilities. In addition, key players in common-pool resource management can be classified into three groups: government, industry, and the community. Previous case studies tended to focus on the roles of a single player among these three. Agrawal and Lemos proposed a new analytical framework called the "hybrid approach", which paid attention to the roles of two or three players in any combination [44]. However, their proposition is a theoretical one and has rarely been applied in groundwater management in general, and even less in groundwater quality management in particular. Thus, the Hadano case, where the city government and the industrial sector coped with groundwater contamination in a cooperative way, also provides a policy model in terms of a hybrid approach.

\section{Conclusions}

This study analyzed the measures against groundwater contamination in Hadano and extracted policy lessons from the experience. Hadano faced three institutional problems when it faced groundwater contamination issues; identification of parties who are responsible for contamination removal, cost sharing among parties, and retrospective application of regulations. Hadano enacted a local ordinance that incorporated proxy cleanup execution, a groundwater purification fund, and retrospective application of regulations. This was a pioneering institution for groundwater quality control in Japan.

Hadano's experience includes a number of policy lessons. First, law for groundwater quality protection needs to include rules for the prevention of contamination and for the cleanup of contamination. Second, groundwater pollution is a stock pollution and the characteristic restricts the applicability of the polluter-pays principle. Third, a flexible combination of multiple cost-sharing principles-the polluter-pays principle and the beneficiary-pays principle-may work to promote rapid cleanup activities. Fourth, solutions to both quantitative and qualitative issues are not distinct in groundwater management. Lastly, soft-path approach and hybrid approach can be extended to water quality issues.

However, there are still unresolved issues. The scope of this paper is limited to groundwater contamination by CVOCs and Hadano's response to the problem. The institutional problems Hadano faced can arise wherever groundwater contamination takes place. Groundwater pollution by CVOCs was revealed in Japan in the 1980s. Hadano was not the only local government that grappled with the problem. Investigations on how other local governments in Japan responded to the same problem should be a future task. In addition, with rapid industrialization in Asian countries, concerns regarding groundwater contamination are increasing. How the institutional problems are solved by the legal systems of Asian countries also needs to be analyzed. Lastly, although this study paid attention to groundwater contamination by CVOCs, appropriate countermeasures may differ depending on the pollutants [45]. For example, while CVOCs spread in a wide area with the flow of groundwater, heavy metals tend to concentrate around the pollution source. Thus, the problem of cost sharing among parties, which was found in the Hadano case, may not arise. This is because the pollution does not move outside of a polluter's site, and cost sharing can be done in such a way that each polluter removes the contamination within their site at their own expense. This implies that different institutional arrangements are needed in accordance with the physical characteristics of the pollutants in question. More case studies should be done to investigate what kind of countermeasures for different pollutants are appropriate, and to better understand and improve groundwater quality management in general. 
Acknowledgments: This work was financially supported by the research project "Fusion of global water resources assessment and social institution studies (Director: Shinjiro Kanae, Tokyo Institute of Technology)" under the Japan Society for the Promotion of Science KAKENHI (Grant-in-Aid for Scientific Research (B)) grant number $15 \mathrm{H} 04047$. Special thanks are due to editor of this journal and three anonymous reviewers for giving valuable comments. In addition, I would like to express my gratitude to Yoshio Tani, Department of Industry and Environment, Hadano, Kanagawa Prefecture, Japan, for providing the data and information. The views presented here are those of the author and should in no way be attributed to Hadano. Responsibility for the text rests entirely with the author.

Conflicts of Interest: The author declares no conflicts of interest.

\section{References}

1. Hardin, G. Tragedy of the commons. Science 1968, 162, 1243-1248. [CrossRef] [PubMed]

2. Agrawal, A. Common resources and institutional sustainability. In The Drama of the Commons; Ostrom, E., Dietz, T., Dolsak, N., Stern, P.C., Stonich, S., Weber, E.U., Eds.; National Academy Press: Washington, DC, USA, 2002; pp. 41-85.

3. Ostrom, E.; Burger, J.; Field, C.B.; Norgaard, R.B.; Policansky, D. Revisiting the commons: Local lessons, global challenges. Science 1999, 284, 278-282. [CrossRef] [PubMed]

4. Lipson, A.J. Efficient Water Use in California: The Evolution of Groundwater Management in Southern California; Rand Corporation: Santa Monica, CA, USA, 1978.

5. Endo, T. Groundwater management: A search for better policy combinations. Water Policy 2015, 17, 332-348. [CrossRef]

6. Glennon, R. Water Follies, Groundwater Pumping and the Fate of America's Fresh Waters; Island Press: Washington, DC, USA, 2002.

7. Ostrom, E. Governing the Commons, The Evolution of Institutions for Collective Action; Cambridge University Press: New York, NY, USA, 1990.

8. Ostrom, E.; Stern, P.C.; Dietz, T. Water rights in the commons. Water Resour. IMPACT 2003, 5, 9-12.

9. Dietz, T.; Dolsak, N.; Ostrom, E.; Stern, P.C. The dramma of the commons. In The Drama of the Commons; Ostrom, E., Dietz, T., Dolsak, N., Stern, P.C., Stonich, S., Weber, E.U., Eds.; National Academy Press: Washington, DC, USA, 2002; pp. 3-35.

10. Muttil, N.; Chau, K.W. Machine learning paradigms for selecting ecologically significant input variables. Eng. Appl. Artif. Intell. 2007, 20, 735-744. [CrossRef]

11. Wang, W.C.; Xu, D.M.; Chau, K.W.; Lei, G.J. Assessment of river water quality based on theory of variable fuzzy sets and fuzzy binary comparison method. Water Resour. Manag. 2014, 28, 4183-4200. [CrossRef]

12. Zhao, M.Y.; Cheng, C.T.; Chau, K.W.; Li, G. Multiple criteria data envelopment analysis for full ranking units associated to environment impact assessment. Int. J. Environ. Pollut. 2006, 28, 448-464. [CrossRef]

13. Trager, S.M. Managing Groundwater Quality and Quantity: Comparative Approaches of Southern California Water Basins. Available online: http:/ / scholar.law.colorado.edu/groundwater-law-hydrology-policy/18 (accessed on 20 February 2016).

14. Blomquist, W. Dividing the Waters, Governing Groundwater in Southern California; ICS Press: San Francisco, CA, USA, 1992.

15. Vrba, J. The impact of aquifer intensive use on groundwater quality. In Intensive Use of Groundwater, Challenge and Opportunities; Llamas, R., Custodio, E., Eds.; A.A. Balkema Publishers: Lisse, The Netherlands, 2003; pp. 113-132.

16. Yoshida, F. Geo-pollution and a clean-up system. Econ. J. Hokkaido Univ. 1996, 25, 61-82.

17. The Industrial Water Law; Act No. 146. The National Diet of Japan: Tokyo, Japan, 11 June 1956. (In Japanese)

18. The Law on Regulation of Groundwater Use in Office Building; Act No. 100. The National Diet of Japan: Tokyo, Japan, 1 May 1962. (In Japanese)

19. Sato, K.; Shichinohe, K.; Ueno, T. Groundwater-related laws in Japan. In Groundwater Management Practices; Findikakis, A.N., Sato, K., Eds.; CRC Press: Leiden, The Netherlands, 2011; pp. 283-294.

20. Japanese Environment Agency. Survey on Groundwater Pollution in 1982; Japanese Environment Agency: Tokyo, Japan, 1983. (In Japanese)

21. Tase, N. Current situation of groundwater contamination in Japan and future tasks. J. Jpn. Soc. Safe Eng. 2012, 51, 290-296. (In Japanese) 
22. The Water Pollution Control Law; Act No. 138. The National Diet of Japan: Tokyo, Japan, 25 December 1970. (In Japanese)

23. Hirata, T.; Nakasugi, O.; Yoshioka, M.; Sumi, K. Groundwater pollution by volatile organochlorines in Japan and related phenomena in the subsurface environment. Water Sci. Technol. 1992, 25, 9-16.

24. Okada, M.; Peterson, S.A. Water Pollution Control Policy and Management: The Japanese Experience; Gyosei: Tokyo, Japan, 2000.

25. Statistics of Hadano in 2014. Available online: https://www.city.hadano.kanagawa.jp/tokei/shise/shokai/ toke/tokeyoran.html (accessed on 25 December 2015). (In Japanese)

26. Comprehensive Groundwater Management Plan (Executive Summary). Available online: https://www.city. hadano.kanagawa.jp/hozen/machi/sekatsu/documents/gaiyou_2015.pdf (accessed on 25 December 2015). (In Japanese)

27. The Hadano Government. Toward a Revival of Clean Groundwater in Hadano Basin; The Hadano Government: Hadano City, Kanagawa Prefecture, Japan, 1998. (In Japanese)

28. Tani, Y. Department of Industry and Environment, Hadano City, Kanagawa Prefecture, Japan. Personal communication, 2015.

29. Administrative Inspection Bureau of General Affairs Agency. Report of Administrative Inspective Result on Water Quality Protection Measures (For Protection of Public Water Area and Groundwater); Printing Bureau of Ministry of Finance: Tokyo, Japan, 1994. (In Japanese)

30. Society for Groundwater Protection. In Introduction to Groundwater; Hokuto Shuppan: Tokyo, Japan, 1993. (In Japanese)

31. The Ordinance on Prevention and Removal of Groundwater Contamination in Hadano; Hadano City Ordinance No. 17; The Hadano City Assembly: Hadano City, Kanagawa Prefecture, Japan; 2; July; 1993. (In Japanese)

32. The Comprehensive Environmental Response, Compensation, and Liability Act of 1980; Public Law 96-510. The Senate and House of Representatives of the USA: Washington, DC, USA, 11 December 1980.

33. Nagayama, K. On the ordinance on prevention and removal of groundwater contamination in Hadano. Curr. Laws Ord. (Toki no Horei) 1994, 1486, 65-81. (In Japanese)

34. Otsuka, T. Allocating cleanup costs of soil contamination. Waste Manag. Resour. 1994, 5, 382-393. (In Japanese) [CrossRef]

35. Tsuda, S. On the institution for groundwater management in Hadano city. J. Groundw. Technol. 2002, 44, 40-51. (In Japanese)

36. Tani, Y. Department of Industry and Environment, Hadano City, Kanagawa Prefecture, Japan. Personal communication, 2016.

37. Kitamura, Y. Environmental Law; Koubundo: Tokyo, Japan, 2011. (In Japanese)

38. Tsuda, S. A battle against groundwater contamination in Hadano city and its achievements. Chem. Substain. Environ. (Kagaku Busshitsu Kankyo) 2011, 109, 13-15. (In Japanese)

39. Current Situation of Countermeasures for Public Environmental Problems in Hadano City, Kanagawa Prefecture, Japan, 2015. Available online: https://www.city.hadano.kanagawa.jp/hozen/documents/h27_ hon.pdf (accessed on 25 December 2015). (In Japanese)

40. The Law on Prevention of Soil Contamination in Agricultural Land; Act No. 139. The National Diet of Japan: Tokyo, Japan, 25 December 1970. (In Japanese)

41. The Law on Cost Allocation for Prevention of Public Environmental Problems; Act No. 133. The National Diet of Japan: Tokyo, Japan, 25 December 1970. (In Japanese)

42. Tsuda, S. Program and action for keeping quality and quantity of underground water in Hadano city. J. Assoc. Rainwater Storage Infiltr. Technol. (Usui Gijutsu Shiryo) 1998, 28, 65-73. (In Japanese)

43. Gleick, P. Global freshwater resources: Soft-path solutions for the 21st century. Science 2003, 302, $1524-1528$. [CrossRef] [PubMed]

44. Agrawal, A.; Lemos, M.C. A green revolution in the making? Environmental governance in the 21st century. Environment 2007, 49, 36-45. [CrossRef]

45. Hara, K. Groundwater contamination and quality management policy in Japan. Int. Rev. Environ. Strateg. 2006, 6, 291-306.

(C) 2016 by the author; licensee MDPI, Basel, Switzerland. This article is an open access article distributed under the terms and conditions of the Creative Commons Attribution (CC-BY) license (http://creativecommons.org/licenses/by/4.0/). 